\title{
Whose mental health declines during economic downturns?
}

\author{
Nicole Black ${ }^{*}$, Angela Jackson ${ }^{2}$, David Johnston ${ }^{1}$ \\ ${ }^{1}$ Centre for Health Economics, Monash Business School, Monash University \\ ${ }^{2}$ Equity Economics and Development Partners
}

\section{Version: October 2021}

\begin{abstract}
Prior research shows that economic downturns are associated with increases in mental illness. However, we know little about whose mental health is most negatively affected. Is it the young or old, men or women, employed or non-employed, rich or poor? Using an 18-year panel dataset of Australians, we contribute to this understanding by estimating the impact of changes in unemployment on mental health, separately by population subgroups. Our mental health measure captures psychological distress and emotional difficulties, which are often missed by infrequent event indicators such as suicides. We find that young women suffer most during economic downturns. Men and women of older ages are not significantly affected. The effects for young women are driven by those in insecure employment, and those from low socioeconomic backgrounds. Our results suggest that public health programs should emphasize the mental health of young women during economic downturns.
\end{abstract}

Key Words: economic conditions; labour market fluctuations; mental health; psychological distress

\footnotetext{
* Corresponding author: Nicole Black Nicole.Black@monash.edu.au

This paper uses unit record data from the Household, Income and Labour Dynamics in Australia (HILDA) Survey. The HILDA Project was initiated and is funded by the Australian Government Department of Social Services (DSS) and is managed by the Melbourne Institute of Applied Economic and Social Research (Melbourne Institute). The findings and views expressed in this paper are those of the authors and should not be attributed to DSS or the Melbourne Institute.
} 


\section{INTRODUCTION}

Prior research shows that economic downturns, including the current COVID-19-induced downturn, are associated with increases in poor mental health outcomes (Ruhm, 2000, 2003, and 2015, Charles and DeCicca, 2008, Breuer 2015, Bradford and Lastrapes, 2014, Avdic, de New, \& Kamhöfer, 2020, Witteveen \& Velthorst 2020). However, we know little about whose mental health is most negatively affected. Is it the young or old, men or women, employed or non-employed, rich or poor? We contribute to this understanding by using Australian panel data to estimate the impact of changes in unemployment within local areas over time on mental health, separately by subgroups. This evidence provides policy-makers with better information to formulate responses during downturns.

Worsening economic conditions impact mental health because job loss and reduced income can increase stress and anxiety, and in turn further affect mental wellbeing through secondary impacts on family, marital and financial difficulties (McKee-Ryan et al. 2005, Browning \& Heinesen 2012). Similarly, uncertainty around future income and fear of job loss can reduce wellbeing (Burgard, Brand \& House 2009, Caroli \& Godard 2016).

Certain population groups may suffer more during economic downturns, and it is important to identify who these groups are. Men tend to have worse labour market outcomes than women during recessions (Hoynes, Miller \& Schaller 2012). However, it is unclear whether this translates into worse mental health. Women suffer from more anxiety and depressive disorders than men (Rosenfield \& Mouzon 2013) and therefore may be more impacted, during downturns. ${ }^{1}$ Effects may also vary by age. For example, younger workers generally have fewer relevant skills, experience, and contacts, and may be less indispensable to firms than senior workers (Bell \& Blanchflower 2011). Employment status and socioeconomic background may

\footnotetext{
${ }^{1}$ Male suicide rates are higher than females in Australia, however, recent evidence suggests these rare fatalities do not appear to be induced by economic downturns (Atalay et al. 2020).
} 
also be important. For example, workers in temporary or insecure positions may be among the first to be laid off, and therefore particularly vulnerable during economic downturns (Green 2011). Individuals from lower socioeconomic backgrounds may have lower financial reserves and less family support to smooth out periods of unemployment.

A major strength of our paper is that we use panel data from 2001-2018 to estimate the impact of changes in unemployment. We also use a comprehensive mental health index, which has the advantage of capturing feelings of psychological distress, mental wellbeing, and limitations due to emotional difficulties. While the literature has more commonly used suicides to measure mental health impacts (e.g. Ruhm 2000, 2003, Phillips and Nugent 2014, Breuer 2015, Atalay et al. 2021), suicide is an extreme event that cannot fully capture psychological suffering (Turecki \& Brent 2016).

The study closest to ours is Charles and DeCicca (2008), which examines whose health is affected by labour market fluctuations in the U.S. We extend this work in several ways. First, we use a panel dataset covering 18 years instead of 5 years of cross-sectional data (1997-2001). Second, we investigate both men and women. Third, we explore whether the mental health impacts operate through realised losses in employment outcomes and financial wellbeing.

\section{DATA}

We use panel data on 13,165 men and 13,763 women aged 20-69 over the period 2001-2018 from the Household, Income and Labour Dynamics in Australia (HILDA) survey; a nationally representative household panel study conducted annually since 2001. Mental health is assessed using information from the Short Form (SF)-36 questionnaire. We perform a factor analysis on the eight SF-36 health subscales and retain two oblique rotated factors, representing physical 
and mental health. ${ }^{2}$ This provides scoring weights that are Australian-specific and contemporary (see Appendix Table A1). Our main mental health outcome is a binary variable indicating the respondent is in the lowest decile of the gender-specific mental health distribution (poor mental health). ${ }^{3}$ For robustness, we also present results using poor mental health indicators generated from a factor analysis of only four SF-36 subscales (vitality, social functioning, emotional role limitations, and mental health), and the single mental health subscale.

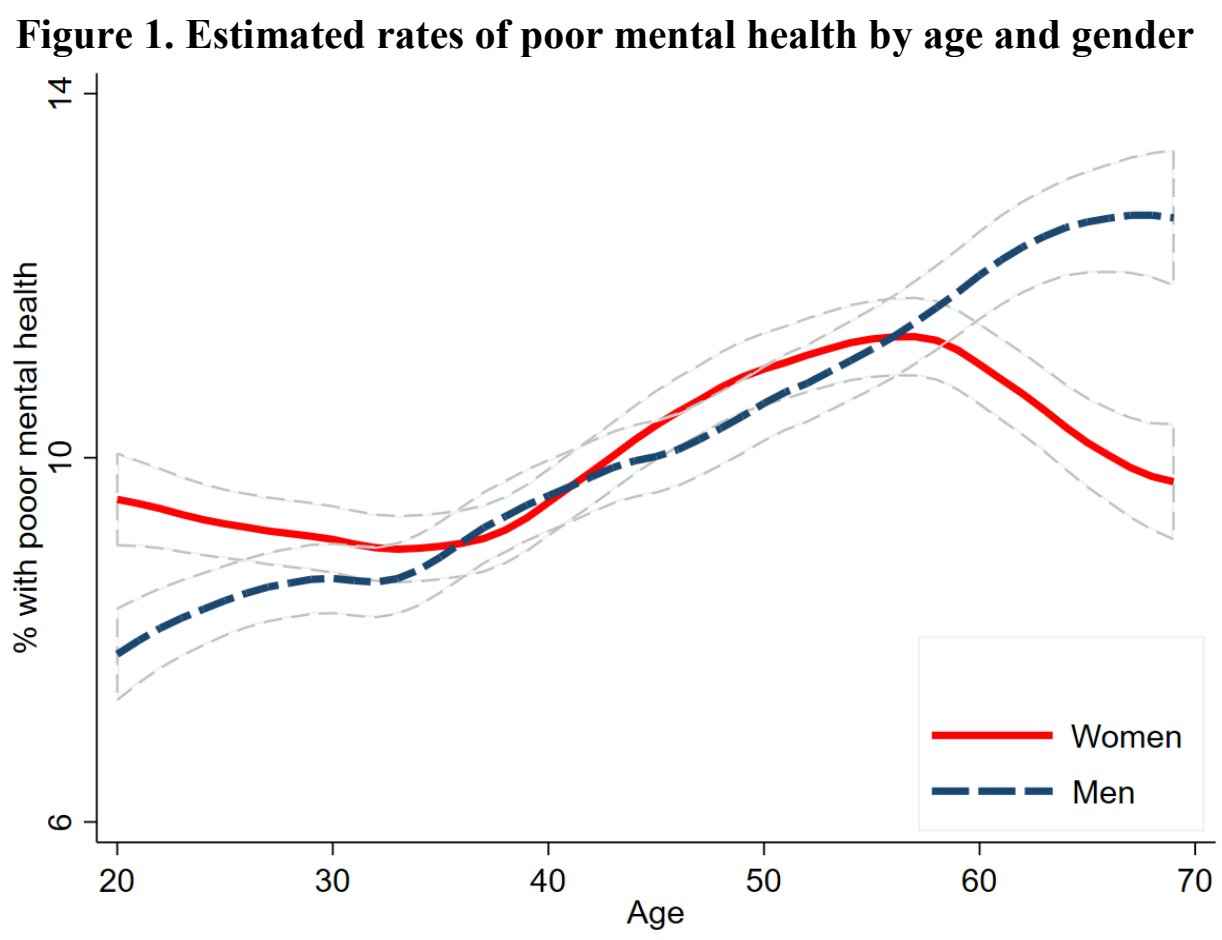

Notes: Proportion with poor mental health and $95 \%$ confidence intervals by age and gender. Poor mental health is defined as the lowest $10 \%$ of the gender-specific distribution of mental health.

\footnotetext{
${ }^{2}$ This approach recognises that there is information regarding a person's true mental health within their responses to the physical health questions (i.e. mental and physical health are not completely independent).

${ }^{3}$ This measure is strongly associated with mental healthcare: $30.4 \%$ of people classified as having poor mental health report mental healthcare in the past 12 months, compared with $5.7 \%$ of all other people. Sensitivity analysis using different cut-offs for poor health suggest that our results are not sensitive to the bottom $10 \%$ cut-off choice (see Appendix Table A5).
} 
Figure 1 presents the proportion of men and women in poor mental health by age. According to our measure, the proportion of men suffering from poor mental health increases steadily with age. Around $8 \%$ of men in their 20 s suffer from poor mental health, compared with almost $13 \%$ of men in their 60s. Women have a different mental health profile. Women experience significantly higher rates of poor mental health than men at younger ages $(<25$ years $)$ and significantly lower rates during older ages ( $>60$ years). At other ages, we cannot reject the null hypothesis at the $5 \%$ level that male and female mental health rates are equal.

\section{METHODS}

The main identification concern is that unobserved characteristics of an area may drive both high unemployment rates and poor mental health. To estimate the effect of unemployment on mental health, we exploit year-to-year variation in unemployment rates within local areas over time (e.g. Ruhm, 2000). Specifically, we estimate a baseline linear regression specification of the form:

$$
m h_{i j t}=\alpha_{j}+\theta_{t}+\delta u r_{j t}+\lambda X_{i j t}+\varepsilon_{i j t}
$$

$m h_{i j t}$ represents poor mental health for person $i$ in area $j$ in year $t$, where areas are 87 substate labour force regions. ${ }^{4}{ } r_{j t}$ represents the area-level unemployment rate in the same month as the respondent was surveyed. The area fixed-effects $\left(\alpha_{j}\right)$ controls for time invariant area characteristics, $\theta_{t}$ accounts for year fixed effects, and $X_{i j t}$ includes age and month-of-year fixed-effects, which control for all age and seasonal factors that influence mental health. Our key parameter, $\delta$ captures the impact of within-area deviations in the unemployment rate on

\footnotetext{
${ }^{4}$ The areas are Statistical Areas Level 4 (SA4), a geographical construct defined by the Australian Bureau of Statistics to represent labour markets or groups of labour markets within each state and territory. In regional areas, SA4s have 100,000-300,000 people. In metropolitan areas, SA4s have 300,000-500,000 people.
} 
poor mental health. To explore heterogeneity in $\delta$, equation (1) is estimated separately for different population subgroups.

We test the sensitivity of our estimates by augmenting equation (1) with: state-year fixedeffects, to control for any state-wide policies or investments over time; area-level linear time trends, to control for differential demographic trends in local areas; and individual fixed-effects, to control for individual time-invariant characteristics (e.g. genetic factors, childhood socioeconomic status) that may influence where people reside and their mental health.

\section{RESULTS}

\subsection{Main estimates}

Figure 2 presents estimated effects of a one percentage-point change in local labour market unemployment on the probability of experiencing poor mental health, separately by gender and age groups. For men, all coefficient estimates are small and statistically insignificant, which suggests that variations in the local unemployment rate do not meaningfully influence male mental health. For women, we also see small and statistically insignificant estimates, with one exception: women aged in their 20's. For this age group, a 5 percentage-point increase in the unemployment rate increases the probability that women experience poor mental health by almost $2\left(=5^{*} 0.39\right)$ percentage-points $(p=0.005) .{ }^{5}$ This represents a $21 \%$ increase relative to the mean for young women $(9.3 \%)$. Notably, A 5 percentage-point within-area change is

\footnotetext{
${ }^{5}$ We have calculated Westfall-Young stepdown adjusted p-values for the estimates presented in Figure 2 using the Stata wyoung program (Jones, Molitor and Reif, 2019). The adjusted p-values indicate that the association between unemployment and poor mental health remains statistically significant at the $5 \%$ level for women aged 20-29.
} 
common within the almost 20 -year period of data, with $94 \%$ of areas having a range greater than $5 . .^{6}$

Our conclusions are robust to the use of alternative mental health indices (see Appendix Table A2). The point estimates are slightly smaller and still statistically significant at the $10 \%$ level. Of the 5 items in the SF-36 mental health domain, the one most strongly impacted by the unemployment rate is "have you felt down?" in the past 4 weeks, suggesting a depressed mood, rather than increased anxiety.

Figure 2: Estimated effects of unemployment on poor mental health by age and gender
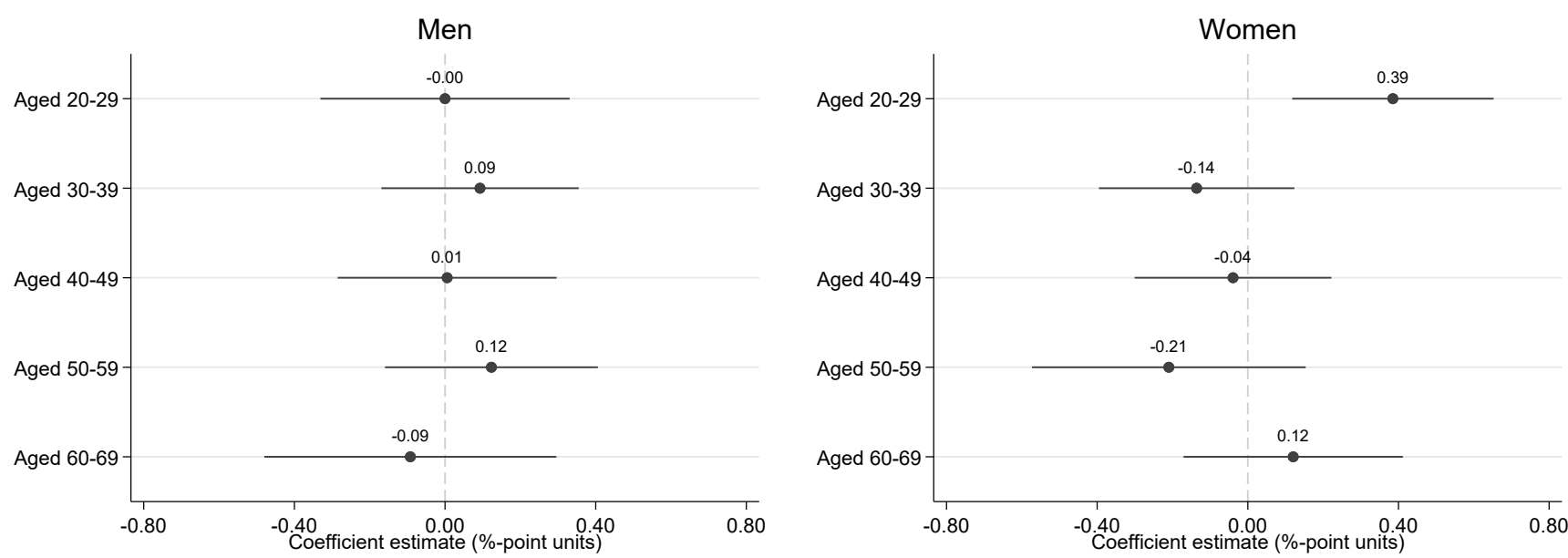

Notes: Coefficient estimates and $95 \%$ confidence intervals, rescaled to be in percentage-point units, are presented in the graphs. All regressions include local area fixed-effects, year fixed effects, and age and month-of-year fixed-effects. The sample sizes for the five male regressions, in ascending age-group order, equal 18776, 18517, 19891, 17804, and 13392. Equivalent sample sizes for the female regressions equal 21302, 21374, 22512, 19858, and 14927.

If we use a continuous index of mental health instead of the binary indicator, a 5 percentagepoint increase in unemployment reduces mental health for young women by only 0.04 of a

\footnotetext{
${ }^{6}$ The estimated impacts are more likely driven by increases in unemployment (economic downturns) than by decreases in unemployment. Negative economic shocks have been shown to have larger impact on mental wellbeing than positive shocks (Boyce et al 2013; Clark et al. 2021)
} 
standard deviation $(p=0.087)$. This smaller effect suggests that higher unemployment increases poor mental health, rather than decreasing good mental health.

The estimates in Figure 2 are robust to the inclusion of additional covariates. When we add state-year fixed-effects, local area linear time trends, or individual fixed effects, a 5 percentagepoint increase in the unemployment rate increases poor mental health by almost 2 percentage points under each specification $(\mathrm{p}<0.05)$ (See Appendix Table A3). Though combinations of area, time and individual fixed-effects are able to control for the majority of confounding factors, there remains the possibility of local-area, time-varying shocks that affect both the economy and mental health. We cannot rule out such shocks, but to explain our results, they would need to impact labour market outcomes of men more than women, and the mental health of young women only.

\subsection{Estimates by employment status}

Given the above results, we now focus our analysis on women aged 20-29 years and explore whether the mental health effects are greater for those who are in less secure employment. Specifically, we estimate the main results separately by whether the young women were nonemployed, employed in a secure job (permanent, ongoing), or employed in an insecure job (casual or fixed-term). ${ }^{7}$ The proportion in each employment category by age and gender is shown in Appendix Table A4.

\footnotetext{
${ }^{7}$ Although employment type is time-varying, it is unaffected by the area unemployment rate in our sample. The estimated unemployment effect for young women equals $0.0004(\mathrm{p}=0.815)$.
} 
Table 1. Impact of unemployment rate on poor mental health for women aged 20-29

\begin{tabular}{lcccc}
\hline & $\begin{array}{c}\text { All Women } \\
\text { Aged }<30\end{array}$ & $\begin{array}{c}\text { Not } \\
\text { Employed }\end{array}$ & $\begin{array}{c}\text { Insecure } \\
\text { Employment }\end{array}$ & $\begin{array}{c}\text { Secure } \\
\text { Employment }\end{array}$ \\
\hline (A) Linear specification & & & & \\
Unemployment rate & $0.385^{* * *}$ & 0.306 & $0.689^{* * *}$ & 0.146 \\
& $(0.135)$ & $(0.232)$ & $(0.228)$ & $(0.188)$ \\
(B) Unemployment & & & & \\
categories & & & & \\
$3 \%<$ UR $\leq 6 \%$ & $1.437^{* *}$ & 0.592 & $3.160^{* * *}$ & 0.398 \\
& $(0.693)$ & $(1.619)$ & $(1.101)$ & $(0.781)$ \\
$6 \%<$ UR $\leq 9 \%$ & $1.883^{* * *}$ & 0.430 & $3.333^{* * *}$ & 1.258 \\
$\quad$ UR $>9 \%$ & $(0.850)$ & $(1.767)$ & $(1.238)$ & $(0.935)$ \\
& $2.816^{* * *}$ & 1.757 & $5.555^{* * *}$ & -0.029 \\
Sample size & $(1.195)$ & $(2.427)$ & $(2.029)$ & $(1.921)$ \\
& & & & 8877 \\
\hline
\end{tabular}

Notes: Dependent variable is poor mental health. Figures are unemployment rate coefficient estimates rescaled to be in percentage-point units. ${ }^{*}, * *$ and $* * *$ denote statistical significance at the $0.10,0.05$ and 0.01 levels respectively. Standard errors clustered at the area level are shown in parentheses. All regressions include local area fixed-effects, year fixed effects, and age and month-of-year fixed-effects.

As shown in Table 1, the results are driven exclusively by women in insecure employment. Panel A shows that an increase in the local area unemployment rate by 5 percentage points increases the probability of poor mental health by 3.5 percentage points $(p=0.003)$. The equivalent estimates for non-employed women and securely employed women are smaller and statistically insignificant.

This finding is not driven by the linear unemployment function in equation (1). At very high unemployment rates $(>9 \%)$ the estimated effects for non-employed women and women in secure employment remain small (see Panel B of Table 1). ${ }^{8}$ In contrast, for women in insecure

\footnotetext{
${ }^{8}$ The percentage of observations in our sample occurring in areas in which the unemployment rate is $<3 \%, 3-6 \%$, $6-9 \%$ and $>9 \%$ equal $9.2 \%, 54.7 \%, 30.8 \%$ and $5.3 \%$, respectively.
} 
employment, we find that unemployment $>9 \%$ is estimated to increase poor mental health by 5.6 percentage points, relative to when unemployment $<3 \%$.

Consistent with Figure 2, estimated unemployment effects for men of all ages and women older than 30 continue to be small and statistically insignificant for all specifications. In Appendix Table A6 we present results for young men by employment type.

Table 2. Impact of unemployment rate on poor mental health for women aged 20-29, separately by family SES and employment groups

\begin{tabular}{cccccc}
\hline Lot & Insecure & Secure & & Not & High SES \\
\cline { 2 - 3 } \cline { 5 - 6 } & Employed & Employment Employment & Secure \\
Employed & Employment Employment \\
\hline
\end{tabular}
A) Linear
Unemployment
$0.579^{*}$
$0.897^{* * *}$
0.204
$-0.106$
0.368
0.033
rate
(0.309)
(0.330)
(0.221)
(0.433)
(0.372)
(0.287)

(B) Non-linear

$\begin{array}{rcccccc}3 \%<\mathrm{UR} \leq 6 \% & 0.583 & 4.297^{* *} & 0.580 & -0.175 & 2.636^{*} & 0.600 \\ & (2.162) & (2.092) & (1.205) & (2.254) & (1.491) & (1.163) \\ 6 \%<\mathrm{UR} \leq 9 \% & 1.262 & 4.645^{* *} & 2.469^{*} & -1.890 & 2.402 & -0.243 \\ & (2.434) & (2.138) & (1.468) & (2.710) & (1.831) & (1.432) \\ \mathrm{UR}>9 \% & 4.902 & 7.512^{* *} & -0.311 & -4.382 & 2.438 & 0.964 \\ & (3.135) & (3.075) & (2.055) & (3.402) & (3.000) & (3.235)\end{array}$

Sample size

3926

3156

4852

2215

3096

4025

Notes: Dependent variable is poor mental health. Figures are unemployment rate coefficient estimates rescaled to be in percentage-point units. All regressions were estimated using the sample of women aged 20-29 years. *, ** and *** denote statistical significance at the $0.10,0.05$ and 0.01 levels respectively. Standard errors clustered at the area level are shown in parentheses. SES is defined as the socioeconomic status of parents based on the Australian Socioeconomic Index, 2006. All regressions include local area fixed-effects, year fixed effects, and age and monthof-year fixed-effects.

In Table 2 we explore whether the results shown in Table 1 differ by family socioeconomic status (SES). Family wealth may provide informal insurance, and therefore young women with high SES parents may feel more economically secure than otherwise similar women with low SES parents; especially during economic downturns. Dividing young women into two groups 
- parents with high and low occupational status ${ }^{9}-$ we find that the effect of unemployment on poor mental health is driven by women in insecure employment from lower SES families. An increase in the unemployment rate by 5 percentage points is estimated to increase the probability of poor mental health among insecure workers from low SES families by 4.5 percentage points $(p=0.008)$.

Although young women in insecure employment experience the largest mental health effects, this does not appear to be due to increased terminations of employment or other negative labour market outcomes. In Table 3, we show that the unemployment rate is not significantly related to being fired or changing jobs within the 12 months following the survey. Similarly, there is a small and statistically insignificant effect on work hours per week, and a near-zero effect on $\log$ weekly wages.

In contrast, it appears that variations in the unemployment rate relate to satisfaction with a person's 'financial situation', measured on a 0-10 scale (see Panel E). An increase in the unemployment rate by 5 percentage points is estimated to reduce the financial satisfaction of young women in insecure employment by 0.24 units $(p=0.013) .{ }^{10}$ These results most likely reflect an increase in economic insecurity and financial stress and support previous evidence of an independent effect of fear of financial insecurity on wellbeing during economic downturns (e.g. Tella, MacCulloch \& Oswald 2003).

\footnotetext{
${ }^{9}$ Respondents are asked to recall their parent's occupation when they were aged 14. Occupational status is measured using the Australian Socioeconomic Index 2006 (AUSEI06). It is a scale of economic status predicted by people's occupation, with laborers at the bottom of the scale and medical practitioners at the top. We take the maximum value of maternal and paternal indices, and divide the sample into high and low values of the index such that the insecure employment sample sizes are similar.

${ }^{10}$ To put this in perspective, estimates from an individual fixed-effects regression indicate that 'being fired' and 'being promoted' during the past year is associated with changes in financial satisfaction equal to -0.46 and 0.34 units respectively. This suggests that for young women in insecure employment, large changes in the local unemployment rate have comparable impacts on financial satisfaction to individual-specific labour market shocks.
} 
Table 3: Impact of unemployment rate on employment and financial wellbeing outcomes for women aged 20-29

\begin{tabular}{lccc}
\hline & $\begin{array}{c}\text { All Women } \\
\text { Aged }<30\end{array}$ & $\begin{array}{c}\text { Insecure } \\
\text { Employment }\end{array}$ & $\begin{array}{c}\text { Secure } \\
\text { Employment }\end{array}$ \\
\hline (A) Fired or made redundant & 0.000 & 0.001 & 0.001 \\
& $(0.001)$ & $(0.002)$ & $(0.001)$ \\
(B) Change employers & -0.001 & -0.006 & 0.000 \\
& $(0.002)$ & $(0.005)$ & $(0.004)$ \\
& $-0.113^{*}$ & -0.147 & -0.027 \\
(C) Weekly work hours & $(0.067)$ & $(0.102)$ & $(0.080)$ \\
& -0.004 & -0.001 & -0.005 \\
(D) Log weekly wages & $(0.003)$ & $(0.006)$ & $(0.004)$ \\
& & & -0.008 \\
& $-0.024^{* *}$ & $-0.048^{* *}$ & $(0.014)$ \\
(E) Financial satisfaction & $(0.011)$ & $(0.019)$ & \\
& & & \\
\hline $\begin{array}{l}\text { Notes: Figures are unemployment rate coefficient estimates from regressions } \\
\text { variables listed in column 1, estimated using the sample of women aged 20-29 years. *** and }\end{array}$ \\
*** denote statistical significance at the 0.10, 0.05 and 0.01 levels respectively. Standard errors \\
clustered at the area level are shown in parentheses. All regressions include local area fixed- \\
effects, year fixed effects, and age and month-of-year fixed-effects.
\end{tabular}

\section{CONCLUSION}

We show that women in their 20's are most likely to suffer poor mental health during economic downturns. Men and women of older ages are not significantly affected. We further demonstrate that the effects for young women are driven by those in insecure employment, in particular, those from low socioeconomic family backgrounds.

As with previous economic downturns, the COVID-19 pandemic has seen more young people lose their jobs than older people, but unlike previous downturns, female-dominated industries have been the hardest hit (International Labour Organization 2021). This suggests that the large mental health effects we find for young women during economic downturns are likely to be even greater during the current economic crisis. 
Mental illness can have a damaging impact on all aspects of our life, and prevention and early intervention are key to containing its impact. Our results suggest a need to focus on programs that support the mental health of young women, particularly those in insecure employment and from low socioeconomic backgrounds, during economic downturns. 


\section{REFERENCES}

Atalay, K., Edwards, R., Schurer, S., \& Ubilava, D. (2021). Lives saved during economic downturns: Evidence from Australia. Health Economics, 1- 16.

Avdic, D., de New, S. C., \& Kamhöfer, D. A. (2020). Economic downturns and mental wellbeing. DICE Discussion Paper No. 337.

Bell, D. N., \& Blanchflower, D. G. (2011). Young people and the Great Recession. Oxford Review of Economic Policy, 27(2), 241-267.

Boyce, C. J., Wood, A. M., Banks, J., Clark, A. E., \& Brown, G. D. (2013). Money, wellbeing, and loss aversion: Does an income loss have a greater effect on well-being than an equivalent income gain?. Psychological science, 24(12), 2557-2562.

Bradford, W. D., \& Lastrapes, W. D. (2014). A prescription for unemployment? Recessions and the demand for mental health drugs. Health economics, 23(11), 1301-1325.

Breuer, C. (2015). Unemployment and suicide mortality: evidence from regional panel data in Europe. Health economics, 24(8), 936-950.

Browning, M., \& Heinesen, E. (2012). Effect of job loss due to plant closure on mortality and hospitalization. Journal of health economics, 31(4), 599-616.

Burgard, S. A., Brand, J. E., \& House, J. S. (2009). Perceived job insecurity and worker health in the United States. Social science \& medicine, 69(5), 777-785.

Caroli, E., \& Godard, M. (2016). Does job insecurity deteriorate health?. Health economics, 25(2), 131-147.

Charles, K. K., \& DeCicca, P. (2008). Local labor market fluctuations and health: is there a connection and for whom?. Journal of health economics, 27(6), 1532-1550.

Clark, A. E., d'Ambrosio, C., \& Zhu, R. (2021). Living in the Shadow of the Past: Financial

Profiles and Well-Being. The Scandinavian Journal of Economics, 123(3), 910-939.

Green, F. (2011). Unpacking the misery multiplier: How employability modifies the impacts of unemployment and job insecurity on life satisfaction and mental health. Journal of health economics, 30(2), 265-276.

Hoynes, H., Miller, D. L., \& Schaller, J. (2012). Who suffers during recessions?. Journal of Economic perspectives, 26(3), 27-48.

International Labour Organization (2021) Assessing the gendered employment impacts of COVID-19 and supporting a gender-responsive recovery, ILO Policy Tool, Available: https://www.ilo.org/employment/Whatwedo/Publications/WCMS 778847/lang-en/index.htm

Jones, Damon, David Molitor, and Julian Reif. "What Do Workplace Wellness Programs Do? Evidence from the Illinois Workplace Wellness Study." Quarterly Journal of Economics, November 2019, 134(4): 1747-1791.

McKee-Ryan, F., Song, Z., Wanberg, C. R., \& Kinicki, A. J. (2005). Psychological and physical well-being during unemployment: a meta-analytic study. Journal of applied psychology, 90(1), 53. 
Phillips, J. A., \& Nugent, C. N. (2014). Suicide and the Great Recession of 2007-2009: The role of economic factors in the 50 US states. Social Science \& Medicine, 116, 22-31.

Rosenfield, S., \& Mouzon, D. (2013). Gender and mental health. In Handbook of the sociology of mental health (pp. 277-296). Springer, Dordrecht.

Ruhm, C. J. (2000). Are recessions good for your health?. The Quarterly journal of economics, 115(2), 617-650.

Ruhm, C. J. (2003). Good times make you sick. Journal of health economics, 22(4), 637-658.

Ruhm, C. J. (2015). Recessions, healthy no more?. Journal of health economics, 42, 17-28.

Tella, R. D., MacCulloch, R. J., \& Oswald, A. J. (2003). The macroeconomics of happiness. Review of Economics and Statistics, 85(4), 809-827.

Turecki, G., \& Brent, D. A. (2016). Suicide and suicidal behaviour. The Lancet, 387(10024), 1227-1239.

Witteveen, D., \& Velthorst, E. (2020). Economic hardship and mental health complaints during COVID-19. Proceedings of the National Academy of Sciences, 117(44), 2727727284. 


\section{Online Appendix}

$\begin{gathered}\text { Appendix Table A1. Factor loadings used to generate physical and mental health } \\
\text { variables }\end{gathered}$
\begin{tabular}{lcc}
\hline Health domains & $\begin{array}{c}\text { Physical } \\
\text { Health }\end{array}$ & $\begin{array}{c}\text { Mental } \\
\text { Health }\end{array}$ \\
\hline Physical functioning & 0.20 & -0.01 \\
Physical role limitation & 0.28 & 0.02 \\
Bodily pain & 0.26 & 0.00 \\
General health & 0.18 & 0.09 \\
Vitality & 0.07 & 0.25 \\
Social functioning & 0.18 & 0.24 \\
Emotional role limitations & 0.03 & 0.15 \\
Mental health & -0.06 & 0.36 \\
\hline
\end{tabular}

Appendix Table A2. Estimated Unemployment Rate Coefficients for Women using Alternative Mental Health Indicators

\begin{tabular}{lcccccc}
\hline & Mean & Age 20-29 & Age 30-39 & Age 40-49 & Age 50-59 & Age 60-69 \\
\hline (1) Main measure & 10.0 & $0.385^{* * *}$ & -0.136 & -0.039 & -0.210 & 0.120 \\
& & $(0.135)$ & $(0.131)$ & $(0.131)$ & $(0.183)$ & $(0.146)$ \\
(2) Four mental subscales & \multirow{2}{*}{9.96} & $0.290^{* *}$ & -0.136 & -0.003 & -0.233 & 0.027 \\
& & $(0.135)$ & $(0.134)$ & $(0.125)$ & $(0.172)$ & $(0.145)$ \\
(3) One mental health & & $0.291^{*}$ & -0.045 & -0.037 & -0.212 & 0.091 \\
subscale & \multirow{2}{*}{11.4} & & & & \\
& & $(0.149)$ & $(0.151)$ & $(0.138)$ & $(0.203)$ & $(0.136)$ \\
(4) Single item: down & \multirow{2}{*}{11.1} & $0.340^{* *}$ & 0.051 & 0.046 & 0.043 & 0.040 \\
& & $(0.142)$ & $(0.150)$ & $(0.121)$ & $(0.185)$ & $(0.118)$ \\
(5) Single item: nervous & \multirow{2}{*}{11.3} & 0.193 & -0.089 & 0.025 & 0.178 & $0.293^{* *}$ \\
& & $(0.170)$ & $(0.169)$ & $(0.154)$ & $(0.181)$ & $(0.126)$ \\
\hline
\end{tabular}

Note: All outcomes equal 100 if person is in a poor mental health state and 0 otherwise. Estimated coefficients can be interpreted in percentage point units for a 1 percentage point change in the unemployment rate. Outcome (2) is based on a factor analysis of the mental health, vitality, social functioning, and role emotional subscales. Outcome (3) is based on the mental health subscale. Outcome (4) indicates feeling 'down' all, most or a good bit of the time in the past 4 weeks. Outcome (5) indicates being a nervous person all, most or a good bit of the time in the past 4 weeks. Standard errors clustered at the area level shown in parentheses. Regressions include local area fixed-effects, year fixed effects, and age and month-of-year fixed-effects. 
Appendix Table A3. Impact of unemployment rate on poor mental health for women aged 20-29, including state-wave fixed effects

\begin{tabular}{|c|c|c|c|c|}
\hline & $\begin{array}{c}\text { Main } \\
\text { Specification } \\
\text { (1) }\end{array}$ & $\begin{array}{c}\text { With } \\
\text { Individual } \\
\text { Fixed-Effects } \\
\text { (2) }\end{array}$ & $\begin{array}{l}\text { With State- } \\
\text { Year Fixed- } \\
\text { Effects } \\
\text { (3) }\end{array}$ & $\begin{array}{c}\text { With Local } \\
\text { Area Linear } \\
\text { Time Trends } \\
\text { (4) }\end{array}$ \\
\hline Unemployment rate & $\begin{array}{c}0.385^{* * *} \\
(0.135)\end{array}$ & $\begin{array}{l}0.342^{* *} \\
(0.141)\end{array}$ & $\begin{array}{l}0.332^{* *} \\
(0.142)\end{array}$ & $\begin{array}{l}0.332^{* *} \\
(0.152)\end{array}$ \\
\hline Sample size & 21302 & 21302 & 21302 & 21302 \\
\hline
\end{tabular}

Appendix Table A4. Proportion of sample by gender and employment status

\begin{tabular}{llllllll}
\hline & \multicolumn{3}{c}{ Women } & & \multicolumn{2}{c}{ Men } \\
\cline { 2 - 4 } \cline { 6 - 7 } & $\begin{array}{l}\text { Not } \\
\text { employed }\end{array}$ & $\begin{array}{l}\text { Insecure } \\
\text { employment }\end{array}$ & $\begin{array}{l}\text { Secure } \\
\text { employment }\end{array}$ & & $\begin{array}{l}\text { Not } \\
\text { employed }\end{array}$ & $\begin{array}{l}\text { Insecure } \\
\text { employment }\end{array}$ & $\begin{array}{l}\text { Secure } \\
\text { employment }\end{array}$ \\
\hline Aged 20-29 & $29.6 \%$ & $29.0 \%$ & $41.4 \%$ & & $23.2 \%$ & $27.2 \%$ & $49.6 \%$ \\
Aged 30-39 & $38.4 \%$ & $18.7 \%$ & $42.9 \%$ & & $24.8 \%$ & $14.9 \%$ & $60.3 \%$ \\
Aged 40-49 & $34.0 \%$ & $19.8 \%$ & $46.2 \%$ & & $32.7 \%$ & $11.9 \%$ & $55.4 \%$ \\
Aged 50-59 & $41.7 \%$ & $15.4 \%$ & $42.9 \%$ & & $42.1 \%$ & $11.3 \%$ & $46.6 \%$ \\
Aged 60-69 & $77.4 \%$ & $7.2 \%$ & $15.4 \%$ & & $73.6 \%$ & $9.3 \%$ & $17.1 \%$ \\
\hline
\end{tabular}

Note: Insecure employment is defined as those who are in casual or fixed-term positions. Secure employment is defined as those in permanent, ongoing positions. 
Appendix Table A5. Impact of unemployment rate on poor mental health for women aged 20-29 by employment status using alternative cut-points to define poor mental health

\begin{tabular}{cccc}
$\begin{array}{c}\text { All Women } \\
\text { Aged }<30\end{array}$ & $\begin{array}{c}\text { Not } \\
\text { Employed }\end{array}$ & $\begin{array}{c}\text { Insecure } \\
\text { Employment }\end{array}$ & $\begin{array}{c}\text { Secure } \\
\text { Employment }\end{array}$ \\
\hline
\end{tabular}
(A) Bottom 5\%
$0.002^{* *}$
0.002
0.003
0.002
$(0.001)$
$(0.002)$
$(0.002)$
$(0.001)$
(B) Bottom 10\%
$0.004^{* * *}$
0.003
$0.007^{* * *}$
0.001
(0.001)
(0.002)
(0.002)
(0.002)
(C) Bottom 15\%
$0.004^{* *}$
0.003
$0.009^{* * *}$
0.001
(0.002)
(0.003)
(0.003)
(0.003)
(D) Bottom 20\%
0.003
0.000
$0.008^{* *}$
0.000
$(0.002)$
(0.004)
(0.004)
(0.003)

\begin{abstract}
Notes: Dependent variable is poor mental health defined by the cut points shown in the four rows. Figures are unemployment rate coefficient estimates. All regressions estimated using the sample of women aged $20-29$ years. $*, * *$ and $* * *$ denote statistical significance at the $0.10,0.05$ and 0.01 levels respectively. Standard errors clustered at the area level shown in parentheses. Regressions include local area fixed-effects, year fixed effects, and age and month-of-year fixedeffects.
\end{abstract}

Appendix Table A6. Impact of unemployment rate on poor mental health for men aged 20-29 by employment status

$\begin{array}{cccc}\text { All men } & \text { Not } & \text { Insecure } & \text { Secure } \\ \text { Aged }<30 & \text { Employed } & \text { Employment } & \begin{array}{c}\text { Employment } \\ \hline\end{array}\end{array}$

(A) Linear specification

Unemployment rate

$\begin{array}{llll}-0.000 & -0.001 & -0.000 & -0.001 \\ (0.002) & (0.004) & (0.003) & (0.002)\end{array}$

(B) Unemployment

categories

$\begin{array}{rcccc}3 \%<\mathrm{UR} \leq 6 \% & 0.005 & 0.001 & 0.003 & 0.005 \\ 6 \%<\mathrm{UR} \leq 9 \% & (0.008) & (0.022) & (0.014) & (0.009) \\ & 0.004 & -0.006 & -0.004 & 0.004 \\ \mathrm{UR}>9 \% & (0.009) & (0.026) & (0.017) & (0.011) \\ & -0.001 & -0.007 & -0.018 & 0.003 \\ & (0.016) & (0.039) & (0.027) & (0.015)\end{array}$

Sample size

18776

4180

5119

9420

Notes: Dependent variable is poor mental health. Figures are unemployment rate coefficient estimates. *, $* *$ and $* * *$ denote statistical significance at the $0.10,0.05$ and 0.01 levels respectively. Standard errors clustered at the area level shown in parentheses. Regression includes local area fixed-effects, year fixed effects, and age and month-of-year fixed-effects. 